\title{
Risk factors for major adverse cardiovascular events after osteoporotic hip fracture repair surgery
}

\author{
M.A. Araguas ${ }^{a}$, A. Herrera ${ }^{\text {b,c,*, I. Garrido }}{ }^{d}$, J. Mateo ${ }^{d}$, A.P. Mayoral ${ }^{e}$, M. Muñoz $^{f}$ \\ a Department of Cardiology, Royo Villanova Hospital, Zaragoza, Spain \\ ${ }^{\mathrm{b}}$ Department of Surgery, University of Zaragoza, Zaragoza, Spain \\ 'Aragón's Health Research Institute, Zaragoza, Spain \\ ${ }^{\mathrm{d}}$ Department of Orthopaedic Surgery and Traumatology, Miguel Servet University Hospital, Zaragoza, Spain \\ ${ }^{\mathrm{e}}$ Health Sciences School, University of Zaragoza, Zaragoza, Spain \\ ${ }^{\mathrm{f}}$ Department of Surgical Specialties, Biochemistry and Immunology, School of Medicine, University of Málaga, Málaga, Spain
}

\section{A R T I C L E I N F O}

Article history:

Accepted 29 March 2020

Available online $\mathrm{xxx}$

\section{Keywords:}

Osteoporotic hip fracture

Cardiac biomarkers

Major adverse cardio-vascular events

\begin{abstract}
A B S T R A C T
Osteoporotic hip fracture (OHF) is an increasingly frequent age-related pathology, which results in high rates of functional loss and mortality within the first year after surgery. This study assessed whether preoperative levels of brain natriuretic peptide (NT-proBNP) and troponin I were related to early occurrence (30d) of major adverse cardio-vascular events (MACE) after OHF repair surgery. During a 6-month period, perioperative clinical and analytical data from consecutive patients, without known history of cardiovascular disease and undergoing surgery for OHF repair at a single centre, were prospectively collected. MACE was defined as acute myocardial ischaemia or infarction, acute heart failure or cardiovascular death. amongst the 140 patients included, 23 (16.4\%) developed postoperative MACE (MACE group) and 117 did not (Control group). Compared to those from control group, patients from MACE group were older, had poorer physical status (ASA III-IV), received preoperative red blood cell transfusion (RBCT) more frequently, presented with lower haemoglobin concentrations and higher NT-proBNP, creatinine and troponin I concentrations. Overall, RBCT requirements and 30d mortality rate were also higher in MACE group. However, in multivariate analysis, only preoperative RBCT, creatinine $>1 \mathrm{mg} / \mathrm{dL}$ and NT-proBNP $>450 \mathrm{pg} / \mathrm{mL}$ remained as independent preoperative risks factors for postoperative MACE, while $95 \%$ confidence intervals of odds ratios were wide. Though our findings require confirmation in a larger multicentre cohort, identifying risk factors for early postoperative MACE after OHF repair surgery, might facilitate assessing patients' risk prior to and following surgery, and targeting them the appropriate preventive and/or therapeutic interventions.
\end{abstract}

(c) 2020 Elsevier Ltd. All rights reserved.

\section{Introduction}

The osteoporotic hip fracture (OHF) is an increasingly frequent age-related pathology, which results in high rates of irreversible functional loss and mortality within the first year after surgery [1-8]. A recent retrospective epidemiological study estimated an overall incidence of 517 cases per 100,000 elderly people per year in Spain [9], whereas a prospective multicentre study reported a $15.8 \%$ overall mortality rate $(24.1 \%$ in men, $13.4 \%$ in women) within the first year, with $53 \%$ of deaths occurring within the first 3

\footnotetext{
th This paper is part of a Supplement supported by The Orthopaedic Surgery and Traumatology Spanish Society (SECOT).

* Corresponding author: Department of Surgery, University of Zaragoza, Domingo Miral, s/n, Zaragoza 50009, Spain.

E-mail address: antonio.herrera@unizar.es (A. Herrera).
}

months [10]. Most common causes of death after OHF were respiratory and cardio-vascular complications; the latter being aggravated the presence of perioperative anaemia [11].

Given the frequency of postoperative cardiac complications in $\mathrm{OHF}$, there is an increasing interest in finding preoperative biomarkers that may identify patients at risk. These biomarkers include cardiac troponins and natriuretic peptides. In clinical practice, cardiac troponins I and $\mathrm{T}$ (as markers of myocardial damage) are mainly used in the diagnosis of acute coronary syndrome, while the brain natriuretic peptides (BNP) (as markers of myocardial stress or myocardial stretch) are mainly used for diagnosing and grading the severity of heart failure [12-14].

Regarding OHF, several studies have shown that preoperative elevations of troponin I $[15,16]$ or $\mathrm{T}[17,18]$ are predictors of postoperative morbidity and mortality in these patients' populations. Similarly, there are several studies evaluating the role of 


\section{List of abbreviations}

\section{OHF: $\quad$ Osteoporotic hip fracture}

$B N P$ : $\quad$ Brain natriuretic peptide

MACE: $\quad$ Major adverse cardio-vascular events

ASA: $\quad$ American Society of Anesthesiologists

RBCT: $\quad$ Red blood cell transfusion

NT-proBNP: N-terminal fragment of pro-BNP

PHF: $\quad$ Pertrochanteric hip fracture

SHF: $\quad$ Subcapital hip fracture preoperative brain natriuretic peptide assessment (especially the N-terminal fragment of pro-BNP [NT-proBNP]), either alone $[19,21]$ or in combination with troponin I determination [22], as a predictor of cardiovascular events in this type of surgery. It has been suggested that NT-proBNP assessment is more reliable than American Society of Anaesthesia (ASA) physical status scale scores for predicting postoperative cardiac complications [23].

However, though the association between elevated preoperative levels of cardiac biomarkers and postoperative cardiovascular complications seemed to be strong, most published studies included mixed populations of OHF patients presenting with or without cardiovascular co-morbidity. Thus, the primary objective of this prospective study was testing the hypothesis that preoperative levels of NT-proBNP and Troponin I may be useful for predicting the occurrence of major postoperative adverse cardiovascular events (MACE: acute myocardial ischaemia or infarction, acute heart failure or cardiovascular death) in OHF patients without known cardiovascular pathology. The possible relationship between MACE and other risk factors such as anaemia or red blood cell transfusion (RBCT) were secondary objectives.

\section{Methods}

\section{Study design}

A prospective study of consecutive patients undergoing surgery for osteoporotic subcapital (SHF) or pertrochanteric (PHF) hip fracture repair at our Centre during a 6-month period was conducted. Upon preoperative admission, the attending orthopaedic surgeon requested the laboratory tests (see below) and patients were screened for eligibility and enrolment by a cardiologist (AA). The study was reviewed, approved and registered by the Committee of Research Ethics of the Autonomous Community of Aragón, Spain (C.P. IACS 81/011-C.I. PI 08/77). All patients or their authorised relatives signed informed consent to enter the study.

\section{Inclusion criteria}

Only patients without a known history of cardiovascular disease, sustaining an OHF due to low-energy trauma, defined as ground level falls up to two levels of stair height [24], and undergoing repair surgery were included. Patients with incomplete data sets for the studied outcomes were also excluded from the analysis.

\section{Perioperative management}

All patients were operated on by the same surgical team, under standardised anaesthesia, antibiotic prophylaxis, and postoperative analgesia. Surgery was scheduled during standard daytime working hours (Monday to Friday), whenever medical staff, operating theatre or blood were available, and if the patient's medical condition allowed it. Neither normovolaemic haemodilution or perioperative cell salvage nor antifibrinolytic drugs were used in any patient. A Gamma 3 trochanteric nail (Stryker Trauma $\mathrm{GmbH}$, Germany) was inserted for fixing PHF, and a cemented hemiarthroplasty (Furlong JRI Orthopaedics, U.K.) or an uncemented total hip arthroplasty (ABG-II, Stryker, USA) for SHF [25].

All patients received closed-suction drains, usually two, which were placed after wound closure and removed the next morning after the operation. The postoperative blood loss in the vacuum collectors was recorded. All stayed in the post-anaesthesia recovery unit for at least $4 \mathrm{~h}$ before being transferred to the ward.

During hospitalization, they were clinically evaluated daily, and full laboratory evaluation was performed preoperatively and at postoperative day 7. After discharge, they attended a followup visit for clinical and laboratory evaluation at postoperative day 30.

Wherever possible, all patients were allowed to sit on the edge of the bed within the first $24 \mathrm{~h}$, and were transferred to a chair during the second postoperative day. Patients were encouraged to stand up, supervised by a physiotherapist, starting then partial weight bearing with walking aids as tolerated, usually at the 34 postoperative day. In the case of PHF considered to be instable (e.g., comminuted postero-lateral femoral fracture), weight bearing was delayed for 4-6 weeks.

Thrombo-prophylaxis was provided by once-daily, weightadjusted dosing of low molecular weight heparin (Enoxaparin, Clexane, Sanofi-Aventis S.A., Barcelona, Spain), which was started $12 \mathrm{~h}$ after surgery and maintained for the first 30 postoperative days.

\section{Stimulation of erythropoiesis}

Unless there were contraindications, patients received: (1) IV iron (200 mg, Venofer, Vifor, Saint Gallen, Switzerland), three doses starting on admission; (2) Vitamin $\mathrm{B}_{12}(1 \mathrm{mg})$ intramuscularly on admission; and (3) Folic acid ( $5 \mathrm{mg} /$ day) for the entire duration of hospitalization. Patients presenting with preoperative haemoglobin levels $<13 \mathrm{~g} / \mathrm{dL}$ also received a single dose of recombinant human erythropoietin (40,000 IU, sc; Eprex, Janssen-Cilag, Madrid, Spain) $24 \mathrm{~h}$ after admission [25].

\section{Transfusion protocol}

The anaesthesiologist made decisions on transfusion, both in the operating theatre and in the anaesthesia recovery unit. On the ward, measurement of postoperative blood loss and decisions on postoperative transfusions were made by the attending surgeon. In these orthopaedic patients, transfusion was considered when the patient had symptoms of acute anaemia (hypotension, tachycardia, tachypnoea, dizziness, fatigue, etc.), or their haemoglobin level felt below $8 \mathrm{~g} / \mathrm{dL}$ [25].

\section{Data collection}

A set of demographic and clinical data was prospectively gathered for all patients, including sex, age, ASA physical status scale, type of OHF, co-morbidities (arterial hypertension, diabetes mellitus, dyslipidaemia), surgical procedure (anaesthesia, duration, type of fracture fixation, drain output), RBCT rate (percentage of transfused patients) and index (RBCT units per patient), occurrence of MACE (myocardial infarction [26], acute cardiac failure [27] and /or cardiovascular mortality) (primary outcome measure), and overall mortality within 30d postoperatively. 
Perioperative laboratory tests were performed in blood samples drawn preoperatively (upon hospital admission) and at postoperative days (POD) 7 and 30, and included: haemoglobin (DXH800 , Beckman Coulter, Brea, CA, USA), iron status and creatinine (AU-5800, Beckman Coulter), troponin I (Unicel DXI 800, Beckman Coulter), NT-proBNP (Cobas 411, Roche Diagnostic, Manheim, Germany). Additionally, $\mathrm{Hb}$ concentration was assessed at POD 1 and at any time during hospitalisation, should it be deemed necessary by the attending physician. Anaemia was defined by haemoglobin $<13 \mathrm{~g} / \mathrm{dL}$ [28-30], irrespective of gender, and ID by TSAT $<20 \%$ and/or ferritin $<100 \mathrm{ng} / \mathrm{mL}$ [29].

\section{Statistical analysis}

As all patients without a known history of cardiovascular disease who underwent surgery for OHF repair during a 6-month period were included in the analysis, the study sample size was not calculated beforehand. Overall, 69 out of 140 patients presented with serum NT-proBNP concentrations $>450 \mathrm{pg} / \mathrm{mL}$. Of those, 19 out 23 (83\%) were in the MACE group and 50 out of 117 (43\%) in the control group. In a post-hoc calculation, the actual size of the study sample provides an alpha error of 0.037 and a statistical power of 0.958 .

Data were expressed as percentages or as the mean \pm standard deviation or median [interquartile range]. Pearson's chi-square test or Fisher's exact test was used for comparison of qualitative variables. Parametric two-way analyses of variance or non-parametric Mann-Whitney $U$ test were used for comparison of quantitative variables, after consideration of distributional characteristics.

Variables with significant differences between groups were introduced in the multivariate analysis (multinomial logistic regression), with MACE as the dependant variable and continuous variables being dichotomised. Established cut-off was used for troponin I ( $>0.03 \mu \mathrm{g} / \mathrm{L})$ [31]. To identify the preoperative NT-proBNP and creatinine cut-off values for predicting the occurrence of postoperative MACE, according to its sensitivity and specificity, the receiver operating characteristic (ROC) curve was used and the area under the curve (AUC) was calculated. For variables showing high collinearity (Pearson's correlation coefficient $>0.7$ ), only one of them was introduced in the multivariate analysis

All statistical analysis were performed with computer software (IBM SPSS 24.0, Chicago, IL), and a p value of less than 0.05 was considered significant.

\section{Results}

A total of 209 patients sustaining OHF (140 PHF, 69 SHF) were admitted to our institution during the 6-month study period. Sixtyseven of them were excluded: 7 treated conservatively and 60 because of a previous history of cardiovascular disease. Additionally, two patients were missed during follow-up (incomplete data). Amongst the remaining 140 (91 PHF, 49 SHF), 23 (16.4\%) developed MACE within 30d postoperatively (MACE group) and 117 did not (Control group).

Demographic, clinical and analytical characteristics are depicted in Tables 1 and 2, and Fig. 1. Preoperatively, patients from MACE group were older $(p=0.053)$, had poorer physical status (ASA IIIIV) $(p=0.022)$ and received RBCT more frequently $(p=0.001)$, compared to those from control group (Table 1). There were also differences in their analytical parameters. Compared to control group, perioperative haemoglobin concentrations were lower in MACE group ( $p=0.001)$, without differences in ferritin or TSAT levels or ID prevalence (Table 2, Fig. 1A-C), whereas NT-proBNP levels were higher (Table 2, Fig. 1D) $(p=0.001)$. Similarly, higher preoperative creatinine $(p=0.001)$ and troponin concentrations $(p=0.02)$ were observed in MACE group, compared to control
Table 1

Demographic and clinical characteristics of hip fracture patients, according to the occurrence of MACE within 30 days postoperatively.

\begin{tabular}{llll}
\hline & Control & MACE & $\mathrm{P}$ \\
\hline Patients (n) & 117 & 23 & \\
Age (years) & $83 \pm 9$ & $87 \pm 8$ & 0.053 \\
Gender (Male/Female) & $18 / 99$ & $7 / 16$ & 0.131 \\
Type of fracture & & & \\
Pertrochanteric, n (\%) & $77(66)$ & $14(61)$ & 0.650 \\
Subcapital, n (\%) & $40(34)$ & $9(39)$ & 0.641 \\
Comorbidity & & & \\
Hypertension, n (\%) & $69(59)$ & $16(69)$ & 0.484 \\
Diabetes, n (\%) & $17(15)$ & $3(13)$ & 1.000 \\
Dyslipidaemia, n (\%) & $17(15)$ & $2(9)$ & 0.739 \\
ASA III-IV & $55(47)$ & $17(74)$ & 0.022 \\
Time-to-surgery (days) & $3.6 \pm 1.6$ & $3.9 \pm 3.4$ & 0.620 \\
RBCT rate, n (\%) & $31(26)$ & $15(65)$ & 0.001 \\
Preoperative, n (\%) & $3(6)$ & $7(30)$ & 0.002 \\
Intraoperative, n (\%) & $3(3)$ & $2(9)$ & 0.070 \\
Postoperative, n (\%) & $30(26)$ & $13(56)$ & 0.018 \\
RBCT index (U/pte) & $0.6 \pm 1.0$ & $1.9 \pm 1.6$ & 0.001 \\
30d mortality, n (\%) & $1(1)$ & $8(35)$ & 0.001 \\
\hline
\end{tabular}

ASA, American Society of Anaesthesia physical status scale; MACE, major adverse cardiovascular event; RBCT, red blood cell transfusion.

Table 2

Laboratory parameters at admission in hip fracture patients, according to the occurrence of MACE within 30 days postoperatively.

\begin{tabular}{llll}
\hline & Control & MACE & $\mathrm{P}$ \\
\hline Patients $(\mathrm{n})$ & 117 & 23 & \\
Haemoglobin $(\mathrm{g} / \mathrm{dL})$ & $12.9 \pm 1.5$ & $11.7 \pm 2.2$ & 0.001 \\
Anaemia, n $(\%)$ & $52(44)$ & $15(65)$ & 0.109 \\
Ferritin $(\mathrm{ng} / \mathrm{mL})$ & $297 \pm 264$ & $295 \pm 142$ & 0.811 \\
Ferritin $<100, \mathrm{n}(\%)$ & $19(16)$ & $2(9)$ & 0.527 \\
TSAT $(\%)$ & $27 \pm 26$ & $18 \pm 21$ & 0.103 \\
TSAT $<20 \%, \mathrm{n}(\%)$ & $56(48)$ & $16(70)$ & 0.054 \\
Iron deficiency, $\mathrm{n}(\%)$ & $59(50)$ & $16(70)$ & 0.090 \\
Creatinine $(\mathrm{mg} / \mathrm{dL})$ & $0.9 \pm 0.3$ & $1.3 \pm 0.8$ & 0.001 \\
Creatinine $>1, \mathrm{n}(\%)$ & $20(17)$ & $12(52)$ & 0.001 \\
Troponin $(\mu \mathrm{g} / \mathrm{L})$ & $0.03 \pm 0.11$ & $0.11 \pm 0.26$ & 0.020 \\
Troponin $>0.03, \mathrm{n}(\%)$ & $10(9)$ & $5(22)$ & 0.074 \\
NT-proBNP $(\mathrm{pg} / \mathrm{mL})$ & $366[198-651]$ & $1160[534-2637]$ & 0.001 \\
NT-proBNP $>450, \mathrm{n}(\%)$ & $50(43)$ & $19(83)$ & 0.001
\end{tabular}

MACE, major adverse cardiovascular event; NT-proBNP, N-terminal fragment of type B natriuretic peptide; TSAT, transferrin saturation; Iron deficiency: ferritin $<100 \mathrm{ng} / \mathrm{mL}$ and/or TSAT $<20 \%$. Data are mean \pm standard deviation or median [interquartile range].

group (Table 2). Overall, RBCT rate and index during hospitalisation $(p=0.001)$ and $30 \mathrm{~d}$ mortality rate $(p=0.001)$ were also higher in the MACE group ( $p=$ Table 1$)$.

To ascertain whether the preoperative variables associated with postoperative MACE in the univariate analysis remained as independent risk factors in a multivariate analysis, they were introduced into a multinomial logistic regression model as dichotomised variables (Yes/no: ASA III-IV, preoperative RBCT, creatinine $>1 \mathrm{mg} / \mathrm{dL}$, troponin $>0.03 \mu \mathrm{g} / \mathrm{L}$, NT-proBNP $>450 \mathrm{pg} / \mathrm{mL}$ ). For NT-proBNP, cut-off level was established at $450 \mathrm{pg} / \mathrm{mL}$ because the ROC curve offered an AUC of 0.773 [0.654-0.893] (sensitivity, 83\%; specificity, 54\%) (Fig. 2A). For creatinine, the cut-off level was established in $1 \mathrm{mg} / \mathrm{dL}$, which is commonly used in clinical practice (sensitivity, $52 \%$; specificity, $78 \%$ ), and was derived from a ROC curve with an AUC of 0.705 [0.654-0.826] (Fig. 2B). The cut-off level for troponin was obtained from the literature (24). As depicted in Table 3 , in the multivariate analysis, only preoperative $\operatorname{RBCT}(p=0.009)$, creatinine $>1 \mathrm{mg} / \mathrm{dL}(p=0.036)$ and NT-proBNP $>450 \mathrm{pg} / \mathrm{mL}(p=0.043)$ remained as independent risks factors associated with the occurrence of postoperative MACE. 

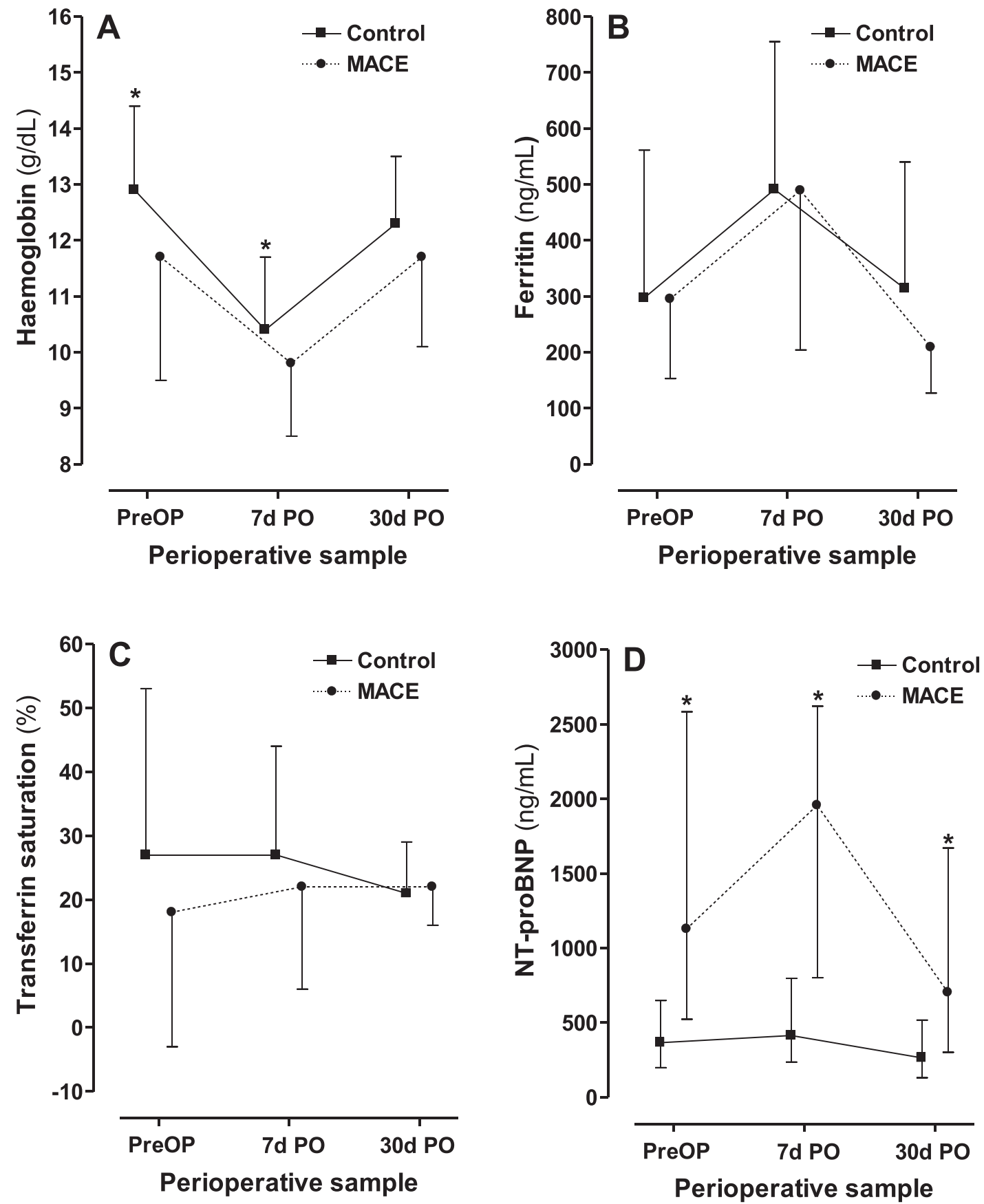

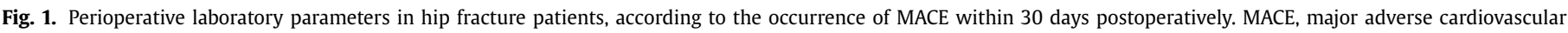

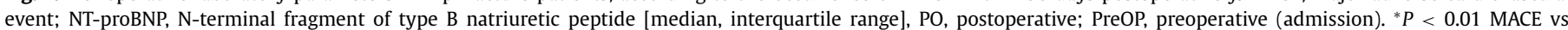
control.

Table 3

Multivariate analysis of preoperative variables associated with MACE (multinomial logistic regression).

\begin{tabular}{|c|c|c|c|c|c|c|}
\hline \multirow{2}{*}{ MACE } & \multirow{2}{*}{ B } & \multirow{2}{*}{ Wald } & \multirow{2}{*}{ Sig. } & \multirow{2}{*}{$\operatorname{Exp}(B)$} & \multicolumn{2}{|c|}{ 95\% Confidence Interval for $\operatorname{Exp}(B)$} \\
\hline & & & & & Lower limit & Upper limit \\
\hline Intersection & -3683 & 29.771 & 0.000 & & & \\
\hline ASA III-IV & 0.949 & 2.697 & 0.101 & 2.584 & 0.832 & 8.020 \\
\hline RBCT preOP & 1.767 & 6.748 & 0.009 & 5.854 & 1.543 & 22.206 \\
\hline Creatinine $>1 \mathrm{mg} / \mathrm{dL}$ & 1.170 & 4.391 & 0.036 & 3.221 & 1.079 & 9.621 \\
\hline NT-proBNP $>450 \mathrm{ng} / \mathrm{mL}$ & 1.346 & 4.084 & 0.043 & 3.840 & 1.041 & 14.163 \\
\hline Troponin $I>0.03 \mu \mathrm{g} / \mathrm{L}$ & 0.339 & 0.221 & 0.639 & 0.713 & 0.174 & 2.928 \\
\hline
\end{tabular}

ASA, American Society of Anaesthesia physical status scale; MACE, major adverse cardiovascular event; NTproBNP, N-terminal fragment of type B natriuretic peptide; RBCT, red blood cell transfusion. 

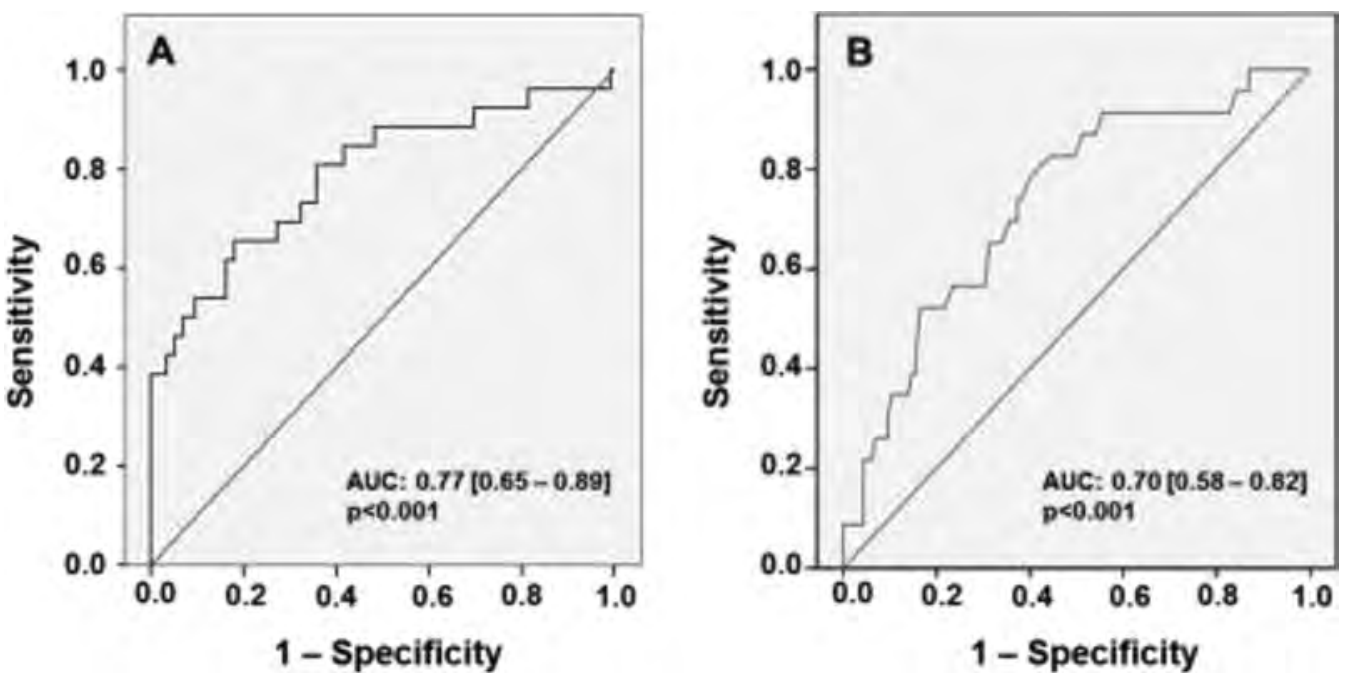

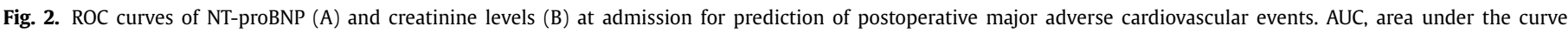
[lower limit-upper limit]; ROC, receiver operator characteristics.

\section{Discusion}

Respiratory and cardio-vascular complications are the most common causes of death after OHF [11]. This study found that preoperative NT-proBNP concentration $>450 \mathrm{pg} / \mathrm{mL}$, preoperative creatinine concentration $>1 \mathrm{mg} / \mathrm{dL}$ and preoperative RBCT were independently associated with an increased odd ratio (OR) for the occurrence of early postoperative major adverse cardiovascular events (MACE), though 95\% confidence intervals [95\%CI] were wide (Table 3). These findings are not completely new [19-23] but, as far as we know, this is the first study documenting a statistically independent association exclusively in a population of OHF patients without a known history of preoperative cardiovascular co-morbidity.

Hip fracture patients presenting with high (>2370 ng/L) or intermediate (806-2370 ng/L) preoperative NT-proBNP concentration has been reported to have higher short-term postoperative mortality ( $<30$ days), compared to those with low NT-proBNP concentration $(<806 \mathrm{ng} / \mathrm{mL})(15 \%$ vs. $11 \%$ vs. $2 \% ; p=0.04)$ [12]. Similar cutoffs of NT-proBNP have been reported by Chong et al. [32,33] for in-hospital cardiac events and 1- and 2-year mortality. However, in these studies, up to $70 \%$ of patients included presented with a history of cardiovascular disease, and were expected to have high rates of postoperative cardiovascular complications. More recently, in a series of $328 \mathrm{OHF}$, the cut-off level of NT-proBNP for predicting postoperative cardiovascular complications, as determined by ROC curve analysis (AUC 0.87 [95\% CI, 0.80-0.94]; $p<0.001$ ), was $600 \mathrm{pg} / \mathrm{mL}$, with a sensitivity, specificity, positive predictive value, and negative predictive value of $79 \%, 81 \%, 25 \%$, and $98 \%$, respectively [21]. Though this cut-off was lower than those previously reported $[25,26]$, again $38 \%$ of OHF patients presented with preoperative cardiovascular co-morbidity. The present study included only patients without a known history of cardiovascular disease, so it is not surprising that an even lower the cut-off level of NT-proBNP $(450 \mathrm{pg} / \mathrm{mL}$ ) was found. This lower cut-off might be reflecting a non-clinically apparent cardiac disease.

Preoperative RBCT was the stronger independent risk factor for postoperative MACE (Table 3). Amongst patients developing MACE, admission Hb levels were significantly lower in those receiving preoperative transfusion compare to those who did not $(9.3 \pm 2.7 \mathrm{~g} / \mathrm{dL}$ vs. $12.7 \pm 1.4 \mathrm{~g} / \mathrm{dL}$, respectively; $p<0.001)$. This suggests the presence of chronic anaemia in this patient subpopulation, in which several compensatory mechanisms may have been activated to improve the tolerance of anaemia. However, many anaesthesiologists are still reluctant to anaesthetize patients presenting with preoperative $\mathrm{Hb}<10 \mathrm{~g} / \mathrm{dL}$. This reluctance prompts the administration of RBCT before taking them to the theatre. The transfused blood is not saturated with oxygen as it enters the circulation and might not confer an immediate positive effect on oxygen delivery (as its oxygen downloading capacity is limited by low 2,3DPG concentrations) [34], while it has an immediate impact on circulatory volume, viscosity and rheological characteristics of recipient's blood (especially in patients with even mild kidney disease). This can lead to various positive and negative changes in macro- and micro-circulation (e.g. transfusion-associated circulatory overload, reduced cardiac output, or improved microcirculation) $[35,36]$, which might be enhanced by subsequent intraand/or postoperative RBCTs (Table 1). Another issue is the change in left ventricular geometry developed in chronic anaemia (such as ventricular hypertrophy) which might be aggravated with RBCT [37].

Iron deficiency, which was very frequent in the study population (54\%, Table 2), may precipitate heart failure [38], which was the cause of death in most cases. As depicted in Table 2, there was a trend towards higher prevalence of iron deficiency in the MACE group compared to the control group. However, as all patients received $600 \mathrm{mg}$ IV iron sucrose perioperatively, the possible role of ID in postoperative heart failure and 30-day mortality is difficult establish. Three randomized trials provide support for the beneficial effects of intravenous iron in patients with heart failure [39], though data from large, independent, and more extended studies are needed [40]. Additionally, the mechanisms underlying non-erythropoietic effects of rHuEPO, such as neurological and renal protective effects, and IV iron, such as improvement of hearth function, need to be elucidated [41,42].

This study presents some limitations. First, this is a singlecentre study and, though this ensured uniform patient care, including aggressive perioperative erythropoiesis management, applicability of the study's findings to other centres might be limited. Second, the whole study sample is relatively small, the follow-up time short. Thus, NT-proBNP assessment might have an important role for the patient whose past history or a reliable exam cannot be obtained. However, confirmation in a larger cohort with a longer follow-up is needed. Third, the absence of a documented history of cardiovascular disease does not exclude conclusively its existence, especially if demographic characteristics and comorbidity of the 
study population are taken into consideration. Thus, apart from the preoperative electrocardiogram, the selection of patients without previous cardiovascular disease could be optimised implementing a non-invasive diagnostic image-based test (echocardiogram), without delaying the procedure, thanks to the coordinated efforts of the Hip Fracture Unit multidisciplinary staff (cardiologist, internist, orthopaedic surgeon, physiotherapist, and anaesthetist). Four, in our series time-to-surgery is clearly over all the international recommendations (with a clear limit established in $48 \mathrm{~h}$ ). However, we did not find differences between patients having surgery within $48 \mathrm{~h}$ and those operated on after $48 \mathrm{~h}$, regarding the incidence of postoperative MACE ( $9 / 42$ vs. $14 / 98 ; p=0.342$ ) or 30 -days mortality (2/42 vs. $7 / 98$, respectively; $p=0.724)$.

In conclusion, despite the above-mentioned limitations, it seems that our data could be useful for everyday clinical practice. Though more research is needed, by identifying significant risk factors associated with early postoperative MACE, the orthopaedic surgeons will be better equipped to assess patients' risk prior to and following surgery, and for targeting them the appropriate preventive or therapeutic interventions.

\section{Declaration of Competing Interest}

All authors declare that they don't have any conflict of interests.

\section{Acknowledgments}

This research has been partially financed by The Fundación Mutua Madrileña (Research Project: AP162632016) and by the Government of Spain, Ministry of Economy and Competitiveness (Research Project: DPI2016-77745-R).

\section{References}

[1] Kanis JA, McCloskey EV, Johansson H, et al. European guidance for the diagnosis and management of osteoporosis in postmenopausal women. Osteoporos Int 2013;24:23-57.

[2] Vun JSH, Ahmadi M, Pantelic M, Pountos I, Giannoudis PV. Dementia and fragility fractures: issues and solutions. Injury, Int. J. Care Injured 2017;48S:S10-16.

[3] Smith M, Giannoudis PV. Fragility fractures: a complex interaction of the health care system- the patient and the bone: can we do better? Editorial. Injury. Int. J. Care Inj 2017;48S:S1-3.

[4] Aldebeyan S, Nooh A, Aoude A, Weber MH, Harvey EJ. Hypoalbuminaemia-a marker of malnutrition and predictor of postoperative complications and mortality after hip fractures. Injury 2017;48:436-40.

[5] Mori CM, Vicenti G, Carrozzo M, Picca G, Bizzoca D, Leone A, Morizio A, Solarino $G$, Moretti B. The fake unlocked femoral nail: a configuration to avoid in stable pertrochanteric femur fractures. Injury 2018;49(Suppl 3 Nov):S32-6.

[6] Mustafa Diab M, Wu HH, Eliezer E, Haonga B, Morshed S, Shearer DW. The impact of antegrade intramedullary nailing start site using the SIGN nail in proximal femoral fractures: a prospective cohort study. Injury 2018;49(Feb (2):323-7.

[7] Rogmark C, Kristensen MT, Viberg B, Rönnquist SS, Overgaard S, Palm H. Hip fractures in the non-elderly-Who, why and whither? Injury 2018;49(Aug (8):1445-50.

[8] Oliveira PR, Leonhardt MC, Carvalho VC, Kojima KE, Silva JS, Rossi F, Lima ALL. Incidence and risk factors associated with infection after intramedullary nailing of femoral and tibial diaphyseal fractures: prospective study. Injury 2018;49(Oct (10):1905-11.

[9] Azagra R, López-Expósito F, Martin-Sánchez JC, Aguyé A, Moreno N, Cooper C, et al. Changing trends in the epidemiology of hip fracture in Spain. Osteoporos Int 2014;25:1267-74. doi:10.1007/s00198-013-2586-0.

[10] Caeiro JR, Bartra A, Mesa-Ramos M, Í Etxebarría, Montejo J, Carpintero P. PROA investigators. Burden of first osteoporotic hip fracture in Spain: a prospective, 12-month, observational study. Calcif Tissue Int 2017;100:29-39. doi:10.1007| s00223-016-0193-8.

[11] Fangke H, Chengying J, Shen J, Peifu T, Yan W. Preoperative predictors for mortality following hip fracture surgery: a systematic review and meta-analysis. Injury 2012;43:676-85. doi:10.1016/j.injury.2011.05.017.

[12] Bajardí A, Cediel G, Carrasquer A, de Castro R, Sánchez R, Boqué C. Troponin elevation in patients without acute coronary syndrome. Rev Esp Cardiol 2015;68:469-76. doi:10.1016/j.rec.2014.10.018.
[13] Maisel AS, Mueller C, Adams K JR, Anker SD, Aspromonte N, Cleland JG, et al. State of the art: using natriuretic peptide levels in clinical practice. Eu J Heart Fail 2008;10:824-39. doi:10.1016/j.ejheart.2008.07.014.

[14] Brunner-La Rocca HP, Sanders-van Wijk S. Natriuretic peptides in chronic heart failure. Card Fail Rev 2019;5:44-9. doi:10.15420/cfr.2018.26.1.

[15] Chong CP, van Gaal WJ, Savige J, Lim WK. Cardiac injury and troponin testing after orthopaedic surgery. Injury 2011;42:855-63.

[16] Sandhu A, Sanders S, Geraci SA. Prognostic value of cardiac troponins in elderly patients with hip fracture - a systematic review. Osteoporos Int 2013;24:11459. doi:10.1007/s00198-012-2116-5.

[17] Spurrier E, Wordsworth D, Martin S, Norris R, Parker MJ. Troponin T in hip fracture patients: prognostic significance for mortality at one year. Hip Int 2011;21:757-61. doi:10.5301/HIP.2011.8840.

[18] Hietala P, Strandberg M, Kiviniemi T, Strandberg N, Airaksinen KE. Usefulness of troponin $\mathrm{T}$ to predict short-term and long-term mortality in patients after hip fracture. Am J Cardiol 2014;114:193-7. doi:10.1016/j.amjcard.2014.04.026.

[19] Nordling P, Kiviniemi T, Strandberg M, Strandberg N, Airaksinen J. Predicting the outcome of hip fracture patients by using $\mathrm{N}$ terminal fragment of pro-B-type natriuretic peptide. BMJ Open 2016;6:e009416. doi:10.1136/ bmjopen-2015-009416.

[20] Katsanos S, Mavrogenis AF, Kafkas N, Sardu C, Kamperidis V, Katsanou P, et al. Cardiac biomarkers predict 1-year mortality in elderly patients undergoing hip fracture surgery. Orthopedics 2017;40:e417-24. doi:10.3928 01477447-20170109-02.

[21] Ushirozako H, Ohishi T, Fujita T, Suzuki D, Yamamoto K, Banno T, et al. Does N-terminal pro-brain type natriuretic peptide predict cardiac complications after hip fracture surgery? Clin Orthop Relat Res 2017;475:1730-6. doi:10.1007/s11999-017-5245-5.

[22] Oscarsson A, Fredrikson M, Sörliden M, Anskär S, Eintrei C. N-terminal fragment of pro-B-type natriuretic peptide is a predictor of cardiac events in high-risk patients undergoing acute hip fracture surgery. $\mathrm{Br} \mathrm{J}$ Anaesth 2009;103:206-12. doi:10.1093/bja/aep139.

[23] Villacorta Junior H, Castro IS, Godinho M, Mattos C, Visconti R, Saud M, et al. B-type natriuretic peptide is predictive of postoperative events in orthopedic surgery. Arq Bras Cardiol 2010;95:743-8.

[24] Konda SR, Seymour R, Manoli A. Development of a middle-aged and geriatric trauma mortality risk score. Bull Hosp Jt Dis 2013;74(4):298-305.

[25] Muñoz M, Gómez-Ramírez S, Cuenca J, et al. Very-short-term perioperative intravenous iron administration and postoperative outcome in major orthopedic surgery: a pooled analysis of observational data from 2547 patients. Transfusion 2014;54:289-99. doi:10.1111/trf.12195.

[26] Thygesen K, Alpert JS, Jaffe AS, Simoons ML, Chaitman BR, White HD, et al. Third universal definition of myocardial infarction. Circulation 2012;126:202035. doi:10.1161/CIR.0b013e31826e1058.

[27] McKee PA, Castelli WP, McNamara PM, Kannel WB. The natural history of congestive heart failure: the Framingham study. N Engl J Med 1971;285:1441-6. doi:10.1056/NEJM197112232852601.

[28] Muñoz M, Gómez-Ramírez S, Kozek-Langeneker S, Shander A, Richards T Pavía J, et al. 'Fit to fly': overcoming barriers to preoperative haemoglobin optimization in surgical patients. Br J Anaesth 2015;115:15-24. doi:10.1093/bja/ aev165.

[29] Muñoz M, Acheson AG, Auerbach M, Besser M, Habler O, Kehlet H, et al. International consensus statement on the peri-operative management of anaemia and iron deficiency. Anaesthesia 2017;72:233-47. doi:10.1111/anae.13773.

[30] Blaudszun G, Munting KE, Butchart A, Gerrard C, Klein AA. The association between borderline pre-operative anaemia in women and outcomes after cardiac surgery: a cohort study. Anaesthesia 2018;73:572-8. doi:10.1111/ anae. 14185.

[31] Jørgensen PH, Nybob M, Jensen MK, Mortensen PE, Poulsen TS, Diederichsen AC, et al. Optimal cut-off value for cardiac troponin I in ruling out Type 5 myocardial infarction. Interactive CardioVascThorac Surg 2014;18:544-50. doi:10.1093/icvts/ivt558.

[32] Chong CP, Ryan JE, van Gaal WJ, Lam QT, Sinnappu RN, Burrell LM, et al. Usefulness of $\mathrm{N}$-terminal pro-brain natriuretic peptide to predict postoperative cardiac complications and long-term mortality after emergency lower limb orthopedic surgery. Am J Cardiol 2010;106:865-72. doi:10.1016/j.amjcard.2010. 05.012.

[33] Chong CP, Lim WK, Velkoska E, van Gaal WJ, Ryan JE, Savige J, et al. N-terminal pro-brain natriuretic peptide and angiotensin-converting enzyme-2 levels and their association with postoperative cardiac complications after emergency orthopedic surgery. Am J Cardiol 2012;109:1365-73. doi:10.1016/j.amjcard.2011. 12.032.

[34] Li Y, Xiong Y, Wang R, Tang F, Wang X. Blood banking-induced alteration of red blood cell oxygen release ability. Blood Transfus 2016;14:238-44. doi:10.2450/ 2015.0055-15.

[35] Agrawal AK, Hsu E, Quirolo K, Neumayr LD, Flori HR. Red blood cell transfusion in pediatric patients with severe chronic anemia: how slow is necessary? Pediatr Blood Cancer 2012;58:466-8. doi:10.1002/pbc.23238.

[36] Zimmerman R, Tsai AG, Salazar Vazquez BY, Cabrales P, Hofmann A, Meier J, Shander A, et al. Posttransfusion increase of hematocrit per se does not improve circulatory oxygen delivery due to increased blood viscosity. Anesth Analg 2017;124:1547-54. doi:10.1213/ANE.0000000000002008.

[37] Eckardt KU, Scherhag A, Macdougall IC, Tsakiris D, Clyne N, Locatelli F, et al. Left ventricular geometry predicts cardiovascular outcomes associated with anemia correction in CKD. J Am Soc Nephrol 2009;20:2651-60. doi:10.1681/ ASN.2009060631. 
[38] Ponikowski P, van Veldhuisen DJ, Comin-Colet J, Ertl G, Komajda M, Mareev V, et al. Beneficial effects of long-term intravenous iron therapy with ferric carboxymaltose in patients with symptomatic heart failure and iron deficiency. Eur Heart J 2015;36:657-68. doi:10.1093/eurheartj/ehu385.

[39] Camaschella C. Iron-Deficiency Anemia. N Engl J Med 2015;372:1832-43. doi:10.1056/NEJMra1401038.

[40] Camaschella C. In response. N Engl J Med 2015;373:484-6. doi:10.1056/ NEJMc1507104.
[41] Muñoz M, Acheson AG, Bisbe E, et al. An international consensus statement on the management of postoperative anaemia after major surgical procedures. Anaesthesia 2018;73:1418-31. doi:10.1111/anae.14358.

[42] Muñoz M, Gómez-Ramírez S, Besser M, Pavía J, Gomollón F, Liumbruno GM, et al. Current misconceptions in diagnosis and management of iron deficiency. Blood Transfus 2017;15:422-37. doi:10.2450/2017.0113-17. 